\title{
Height and Bone Phenotype of 22q11.2 Deletion Syn- drome: Lessons from the Gene Analysis of Three Cases
}

\author{
Bu Kyung Kim¹, Young Bae Sohn², Sang-Jin Park ${ }^{3}$, Shin-Young Yim ${ }^{4}$ and Yoon-Sok Chung $2,5 *$ \\ ${ }^{1}$ Department of Internal Medicine, Kosin University College of Medicine, Busan, Korea \\ ${ }^{2}$ Departments of Medical Genetics, Ajou University School of Medicine, Suwon, Korea \\ ${ }^{3} \mathrm{MG}$ Med, Inc. Seoul, Korea \\ ${ }^{4}$ Physical Medicine and Rehabilitation, Ajou University School of Medicine, Suwon, Korea \\ ${ }^{5}$ Endocrinology and Metabolism, Ajou University School of Medicine, Suwon, Korea
}

This report describes three cases of 22q11.2 deletion syndrome (22q11.2DS) diagnosed by array comparative genomic hybridization with final adult height and bone phenotype. The cases involved a 57-year-old woman with hypocalcemic seizure, an 18-year-old man with short stature, and a 24-year-old woman incidentally diagnosed as 22q11.2DS. The first two patients revealed short stature and low bone mineral density, and their deletion sites included the $T B X_{1}$. The third patient had normal stature and normal bone mineral density, and the deletion site did not include the $T B X_{1}$. The deletion of specific genes including the $T B X_{1}$ could be an important factor of skeletal development including height and bone mineral density of 22q11.2DS.

Key words: 22q11.2 deletion syndrome, Height, Bone

\section{Introduction}

Deletion 22q11.2 (22q11.2DS) is the most common microdeletion syndrome in human, with a minimum prevalence rate of one in 4,000 live births. ${ }^{1,2)}$ Nomenclatures for 22q11.2DS include velocardiofacial syndrome, DiGeorge syndrome, and CATCH22 (cardiac anomaly, abnormal face, thymic hypoplasia, cleft palate, hypocalcemia) syndrome. These various nomenclatures reflect the myriad of clinical features. ${ }^{3-6)}$ Short stature is one of the most common clinical features of 22q11.2DS. However, it is unclear whether short stature is an intrinsic manifestation of this syndrome, or whether it is secondary to other clinical features. ${ }^{7.8)}$ Herein we report three cases of 22q11.2DS diagnosed by whole genome array comparative genomic hybridization (array CGH) using com $\neg$ mercially available array-CGH slides (MACArray Karyo 1440 BAC-chip; Macrogen, Seoul, Korea). We also investigated the genotype-phenotype correlation, especially focused on genomic deletion size, final adult height, and bone mineral density (BMD).

\section{Case}

The first case was a 57-year-old woman who visited the emergency room due to seizure. She had a 2-week history of tetany on both hands. There was no previous history of seizure. Laboratory testing results revealed hypocalcemia $(5.3 \mathrm{mg} / \mathrm{dL}$; 8.2-10.23 mg/dL), elevated serum phosphate ( $5.5 \mathrm{mg} / \mathrm{dL} ; 2.7-4.5$

\footnotetext{
Received: 5 December 2013, Revised: 24 December 2013, Accepted: 24 December 2013, Published: 31 December 2013

${ }^{*}$ Corresponding author: Yoon-Sok Chung, M.D., Ph.D.

Department of Endocrinology and Metabolism, Ajou University School of Medicine, San 5 Wonchon-Dong, Yeongtong-Gu, Suwon, 443-721, South Korea Tel: +82-31-219-5125, Fax: +82-31-219-449, E-mail: yschung@ajou.ac.kr

Conflict of interest: We declare that we do not have any conflicts of interests.

(c) This is an open-access article distributed under the terms of the Creative Commons Attribution Non-Commercial License (http://creativecommons.org/licenses/by-nc/3.0/) which permits unrestricted non-commercial use, distribution, and reproduction in any medium, provided the original work is properly cited.

(c) Copyright 2013 by the Korean Society of Medical Genetics

www.e-kjgm.org
} 
$\mathrm{mg} / \mathrm{dL}$ ), and low values for parathyroid hormone (8 pg/mL; 11-62 $\mathrm{pg} / \mathrm{mL})$, and $25-\mathrm{OH}$-Vitamin $\mathrm{D}_{3}(2.1 \mathrm{ng} / \mathrm{mL} ; 9.0-37.6 \mathrm{ng} / \mathrm{mL})$. She had left kidney agenesis and hearing impairment in both ears (right: $50 \mathrm{~dB}$, left: $40 \mathrm{~dB}$ ). The intelligence quotient (I0) was below average ( $<85)$; especially, verbal IO was delayed. Osteoporosis was evident, with a BMD T score of -4.0. The patient's height was $150 \mathrm{~cm}$ and her weight was $43 \mathrm{~kg}$ lower than the $3^{\text {rd }}$ percentile. After supplementation with calcium and vitamin D, the patient's mental status became alert and tetany was improved. A $0.9 \mathrm{Mb}$ deletion $(19,030,620-19,962,449)$ (Fig. 1A) contained TBX, was detected on chromosome 22q11.2 (Fig. 2A).

The second case was an 18-year-old man who visited an outpatient department with the chief complaint of short stature. His past history included cardiac surgery at 1-month-of-age, diagnosis as velopharyngeal insufficiency at the age of 6 , and three incidents of fracture. His height was $156.5 \mathrm{~cm}$ lower than the $3^{\text {rd }}$ percentile and weight was $51 \mathrm{~kg}\left(3^{\text {rd }}\right.$ to $5^{\text {th }}$ percentile). Pubertal status was normal. The level of $25-\mathrm{OH}$-Vitamin $\mathrm{D}_{3}$ was low $(6.7 \mathrm{ng} / \mathrm{mL})$ and other laboratory test was normal. Serum IGF-I level was normal and the result of insulin-induced growth hormone stimulation test was normal. Although his bone age was 18 years, his lumbar spine BMD was $0.844 \mathrm{~g} / \mathrm{cm}^{2}$ and femoral neck BMD was $0.754 \mathrm{~g} / \mathrm{cm}^{2}$, which were lower than age matched reference values (18-year-old male spine $1.154 \pm 0.098 \mathrm{~g} / \mathrm{cm}^{2}$, femur neck 1.106 $\left.\pm 0.119 \mathrm{~g} / \mathrm{cm}^{2}\right) .{ }^{9)} \mathrm{A} 2.1 \mathrm{Mb}$ deletion $(19,030,620$ $21,176,652)$ (Fig. 1B) contained the $T B X$, was detected on chromosome 22q11.2 (Fig. 2B).

The last case was a 24-year-old woman who visited department of Physical Medicine and Rehabilitation to obtain a medical certificate of disability. She had a growth delay until 3-monthsof-age and feeding difficulty. She had a history of surgery for a cleft palate at 9-years-of-age. The level of 25-OH-Vitamin $\mathrm{D}_{3}$ was low $(5.6 \mathrm{ng} / \mathrm{mL})$ and other laboratory test was normal. She had a speech and language developmental disorder. Her BMD was normal, her height was $165.9 \mathrm{~cm}\left(75^{\text {th }}\right.$ to $90^{\text {th }}$ percentile) and her weight was $74.7 \mathrm{~kg}$ (more than 95th percentile). A $0.3 \mathrm{Mb}$ deletion $(19,030,620-19,372,279)$ (Fig. 1C) did not contain the TBX, was detected on chromosome 22q11.2 (Fig. 2C).

\section{Discussion}

Although short stature is one of the most common clinical features of 22q11.2DS, the mechanism is unclear. In infancy, the growth pattern in the 22q11.2DS is slow. Several studies reported final adult heights are usually in the normal range. ${ }^{3,10)}$ However, an analysis of the growth charts from 188 patients reported that adults with this syndrome remained below the 2 nd percentile
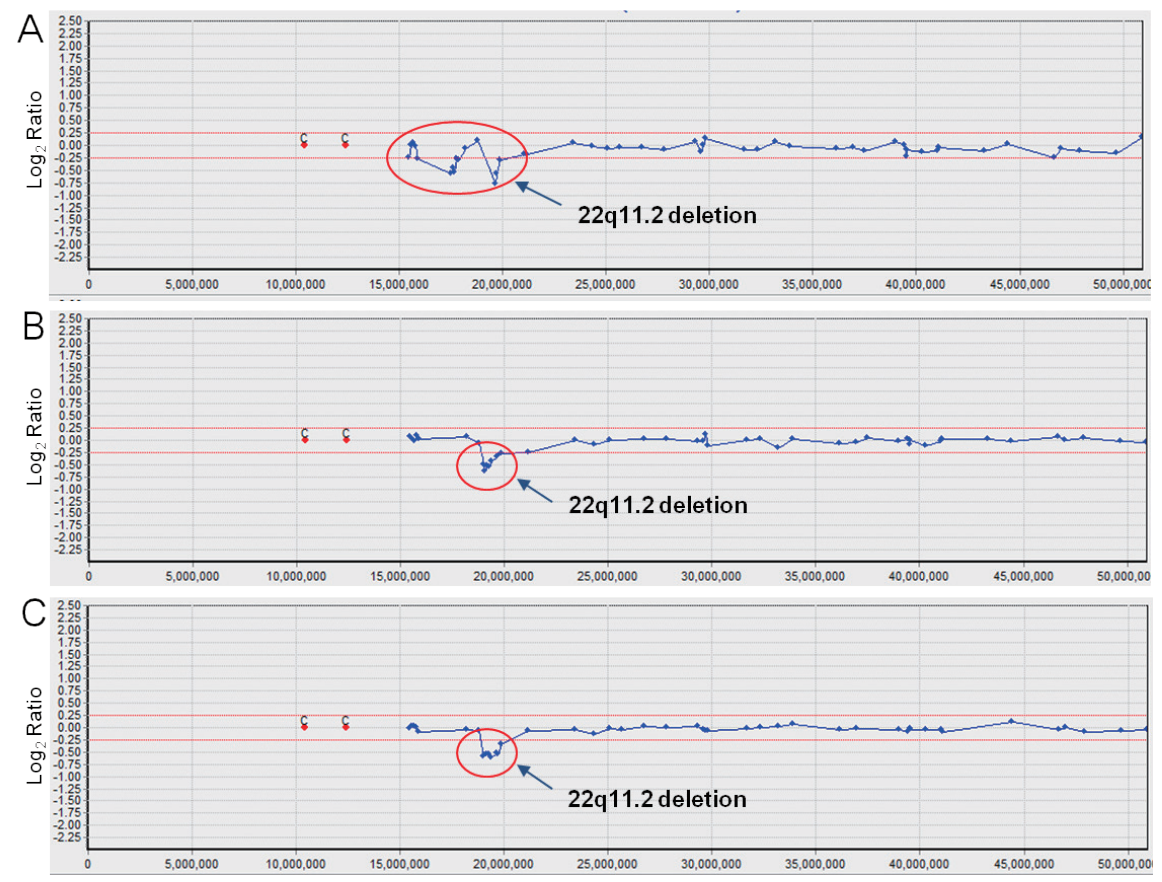

Fig. 1. Array CGH profile from chromosome 22 shows a deletion on the long arm. Arrow indicates a deletion at chromosome 22q11.2. The position of the array CGH was based on NCBI human genome build 37 (GRCh37/hg19; Feb. 2009). (A) The internal boundary is 19,030,620$19,962,449$, and its size is $0.9 \mathrm{Mb}$. (B) The internal boundary is $19,030,620-21,176,652$, and its size is $2.1 \mathrm{Mb}$. (C) The internal boundary is $19,030,620-19,372,279$, and its size is $0.3 \mathrm{Mb}$. 


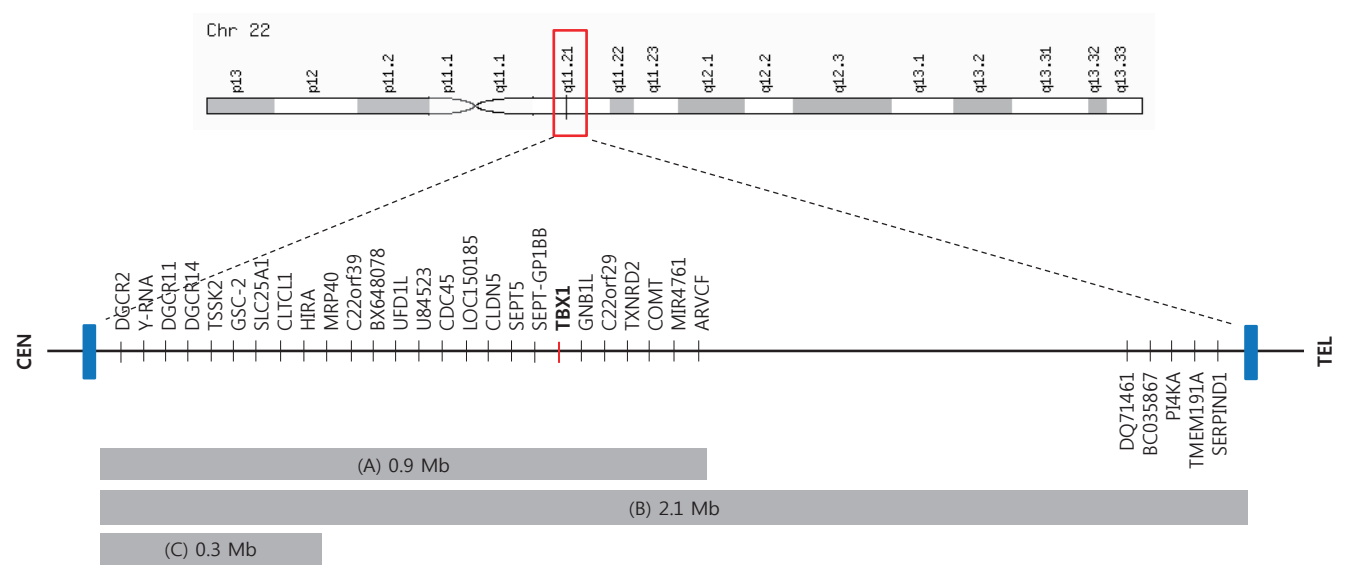

Fig. 2. $T B X_{1}$ gene present on chromosome 22q11.2. The start and end points of this gene are 19,744,226 bp and $19,771,116 \mathrm{bp}$, respectively, and its size is 26,891 bases. (A) Deletion site of case 1 , which includes $T B X_{1}$. (B) Deletion site of case 2, which includes $T B X_{1}$. (C) Deletion site of case 3, which not includes $T B X_{1}$.

for the normal population. Average heights for male and female adults were $167.2 \mathrm{~cm}$ and $158.2 \mathrm{~cm}$, respectively. Another paper reported that final adult heights were $166 \mathrm{~cm}$ and $152 \mathrm{~cm}$, respectively. ${ }^{7)}$ Two patients of this report were shorter than these reference values. These two cases had low BMD with or without hypoparathyroidism and hypocalcemia.

Bone mass and metabolism of the patients with 22q11.2DS are almost unknown. Stagi et al. ${ }^{11)}$ reported that patients with 22q11.2DS had reduced bone mass measured by bone mineral apparent density. The reduction of bone mass worsened with age in adults. The authors explained that lower bone mass was probably due to reduced bone modeling during childhood, which would result in a reduced peak bone mass, posing a significant risk of impaired bone mass in adulthood. ${ }^{111}$ Hypoparathyroidism and hypocalcemia are also frequent manifestations in 22q11.2DS, although are the insufficient cause of reduced BMD. Post-surgical hypopatathyroidism as well as idiopathic hypoparathyroidism increases BMD. ${ }^{12-14)}$ Therefore, the causes of reduced bone mass in 22q11.2DS may be multifocal.

Previous studies reported $50 \%$ to $80 \%$ of the variance in bone mass is genetically determined. ${ }^{15-17)} \mathrm{A}$ Caucasian genome wide linkage study suggested lumbar spine BMD is affected by chromosome $22 q 11-12 .{ }^{18)}$ Therefore, deletion of $22 q 11$ may be an important factor of reduced $B M D$. The $T B X$, is most important factor of pathogenesis of 22q11.2DS. TBX, is expressed at cardiac outflow, pharyngeal mesenchyme, and endodermal pouch. Therefore, deletion of this gene could lead to most of the phenotypes of 22q11.2DS6. TBX, is also expressed in the sclerotome, which differentiates to the spinal column. ${ }^{19)}$ Fulcoli et al. ${ }^{20)}$ reported that TBX, contributes to the BMP/Smad1 pathway, which could affect osteoblast differentiation. These results suggest $T B X_{1}$ could be a factor of reduced BMD of 22q11.2DS. The third case in this paper was of normal stature and had normal BMD. Her deletion site did not include the $T B X_{1}$.

The association $T B X_{1}$ and short stature is already known however the mechanism has not been understood. We reviewed all common gene of two cases with short stature and low BMD. There was no gene which has the possibility of direct effect to bone metabolism except TBX, Here, we report only three cases, so it may be incidental.

Nevertheless, the possibility of the influence of $T B X_{1}$ to bone metabolism is interesting. Short stature could be a result of low bone mass, influenced by the TBX. Analyses of gene array and matched clinical phenotype of 22q11.2DS in large number of patients could increase the understanding of this important genetic disorder.

\section{References}

1. Wilson DI, Burn J, Scambler P, Goodship J. DiGeorge syndrome: part of CATCH 22. J Med Genet 1993;30:852-6.

2. Stalmans I, Lambrechts $D$, De Smet F, Jansen $S$, Wang J, Maity $S$, et al. VEGF: a modifier of the del22q11 (DiGeorge) syndrome? Nat Med 2003; 9:173-82.

3. Ryan AK, Goodship JA, Wilson DI, Philip N, Levy A, Seidel H, et al. Spectrum of clinical features associated with interstitial chromosome 22q11 deletions: a European collaborative study. J Med Genet 1997;34: 798-804.

4. McDonald-McGinn DM, Kirschner R, Goldmuntz E, Sullivan K, Eicher $P$, Gerdes $\mathrm{M}$, et al. The Philadelphia story: the 22q11.2 deletion: report on 250 patients. Genet Couns 1999;10:11-24.

5. Shprintzen RJ. Velo-cardio-facial syndrome: 30 Years of study. Dev 
Disabil Res Rev 2008;14:3-10.

6. Kobrynski LJ, Sullivan KE. Velocardiofacial syndrome, DiGeorge syndrome: the chromosome 22q11.2 deletion syndromes. Lancet 2007; 370:1443-52.

7. Guzman ML, Delgado I, Lay-Son G, Willans E, Puga A, Repetto GM. Growth in Chilean infants with chromosome 22q11 microdeletion syndrome. Am J Med Genet A 2012;158A:2682-6.

8. Tarquinio $\mathrm{DC}$, Jones $\mathrm{MC}$, Jones $\mathrm{KL}$, Bird LM. Growth charts for $22 \mathrm{q} 11$ deletion syndrome. Am J Med Genet A 2012;158A:2672-81.

9. Lim JS, Hwang JS, Lee JA, Kim DH, Park KD, Cheon GJ, et al. Bone mineral density according to age, bone age, and pubertal stages in korean children and adolescents. J Clin Densitom 2010;13:68-76.

10. Digilio MC, Marino B, Cappa M, Cambiaso P, Giannotti A, Dallapiccola B. Auxological evaluation in patients with DiGeorge/velocardiofacial syndrome (deletion 22q11.2 syndrome). Genet Med 2001;3:30-3.

11. Stagi S, Lapi E, Gambineri E, Manoni C, Genuardi M, Colarusso G, et al. Bone density and metabolism in subjects with microdeletion of chromosome 22q11 (del22q11). Eur J Endocrinol 2010;163:329-37.

12. Duan Y, De Luca $V$, Seeman E. Parathyroid hormone deficiency and excess: similar effects on trabecular bone but differing effects on cortical bone. J Clin Endocrinol Metab 1999;84:718-22.

13. Amrein $\mathrm{K}$, Dimai HP, Dobnig H, Fahrleitner-Pammer A. Low bone turnover and increase of bone mineral density in a premenopausal woman with postoperative hypoparathyroidism and thyroxine suppressive therapy. Osteoporos Int 2011;22:2903-5.

14. Chan FK, Tiu SC, Choi KL, Choi CH, Kong AP, Shek CC. Increased bone mineral density in patients with chronic hypoparathyroidism. J Clin Endocrinol Metab 2003;88:3155-9.

15. Krall EA, Dawson-Hughes B. Heritable and life-style determinants of bone mineral density. J Bone Miner Res 1993;8:1-9.

16. Pocock NA, Eisman JA, Hopper JL, Yeates MG, Sambrook PN, Eberl S. Genetic determinants of bone mass in adults. A twin study. J Clin Invest 1987;80:706-10.

17. Gueguen $R_{1}$ Jouanny P, Guillemin F, Kuntz $C_{1}$ Pourel J, Siest G. Segregation analysis and variance components analysis of bone mineral density in healthy families. J Bone Miner Res 1995;10:2017-22.

18. Kaufman JM, Ostertag A, Saint-Pierre A, Cohen-Solal M, Boland A, Van Pottelbergh I, et al. Genome-wide linkage screen of bone mineral density (BMD) in European pedigrees ascertained through a male relative with low BMD values: evidence for quantitative trait loci on 17q21-23, 11q1213, 13q12-14, and 22q11. J Clin Endocrinol Metab 2008;93:3755-62.

19. Mahadevan NR, Horton AC, Gibson-Brown JJ. Developmental expression of the amphioxus Tbx1/ 10 gene illuminates the evolution of vertebrate branchial arches and sclerotome. Dev Genes Evol 2004;214:559-66.

20. Fulcoli FG, Huynh T, Scambler PJ, Baldini A. Tbx1 regulates the BMPSmad1 pathway in a transcription independent manner. PLoS One 2009; 4:e6049. 